\title{
A ação docente empreendedora em cursos tecnológicos e os princípios da
}

\section{autonomía}

\section{The entrepreneurial teaching action in technological courses and the principles of autonomy}

\author{
Vanessa Gatto Chimendes*, Rita de Cássia M.T. Stano** \\ *Universidade Estadual Júlio de Mesquita Filho, **Universidade Federal de Itajubá
}

\begin{abstract}
Resumo
A utilização do conhecimento e a exploração de novas possibilidades de educação, somadas à pesquisa, aos avanços científicos e tecnológicos são, necessários na busca de outros caminhos para as atividades acadêmicas. Este artigo apresenta o mapeamento dos docentes de uma unidade de formação tecnológica e suas possíveis práticas de ensino voltadas à inovação e empreendedorismo. Foi utilizado questionário, entrevistas e análise de documentos. Os participantes são os docentes de uma faculdade de tecnologia. Com o resultado encontrado pode-se gerar propostas concretas para a construção de uma docência fundada nos princípios da Pedagogia da Autonomia a partir de um caráter emprendedor.

Palabras clave: docência, pedagogia da autonomia, habilidades empreendedoras
\end{abstract}

\begin{abstract}
The use of knowledge and the exploration of new possibilities of education, combined with research, scientific and technological advances are necessary in the search for other paths to academic activities. This article presents the mapping of the teachers of a technological training unit and its possible teaching practices focused on innovation and entrepreneurship. Questionnaire, interviews and document analysis were used. The participants are the faculty of a technology college. With the result found it can be generated concrete proposals for the construction of a teaching founded on the principles of Pedagogy of Autonomy from an entrepreneurial character. Keywords: teaching, autonomy pedagogy, entrepreneurial skills
\end{abstract}

\section{Introdução}

A questão fundamental que se coloca é: como preparar o jovem para o mercado e além dele? É imprescindível manter $o$ foco em uma educação que vise o desenvolvimento social por meio do pensamento crítico, reflexivo, em uma atitude empreendedora, não apenas na formação e criação de novas empresas (não descartando também esta característica), mas lembrando, o papel do empreendedor em produzir e introduzir inovações, propostas e formas diferentes de introduzir práticas reorganizando os recursos e produzindo ganho. Trata-se da inserção de um sujeito ativo e atuante positivamente na sociedade. E também com um planejamento educacional com uma visão para o conceito de empreendedorismo de Schumpeter (1982) (desenvolvimento econômico se dá por meio da introdução de novas formas de atuar sobre os recursos com ganhos econômicos).

Para Chimendes (2011), com a contribuição da ciência cada vez mais na esfera direta das forças produtivas, o conhecimento tornou-se essencial para a geração de riqueza e para a promoção do bem-estar social. Fica difícil imaginar o processo industrial sem Ciência e Tecnologia. A inovação é um dos principais fatores para que o emprego e a empresa não entrem em um estado estacionário rumo à extinção. $\mathrm{O}$ fortalecimento da capacidade inovadora do país, com a crescente utilização da tecnologia gerada internamente, faz com que a Tecnologia, no sentido econômico, seja um bem passível de comercialização.

Considerando que o papel primordial do Tecnólogo está voltado para a solução de problemas no mundo do trabalho, e para a inovação, a capacidade empreendedora se torna ferramenta fundamental para essa atuação. Assim, a Faculdade de Tecnologia - FATEC Guaratinguetá, uma unidade do ensino superior tecnológico pertencente ao Centro Paula Souza, mantida pelo Governo do Estado de São Paulo, prepara profíssionais com qualificação específica, pragmática e voltada ao mercado de trabalho A unidade, objeto de estudo, possui seis cursos de formação tecnológica, sendo eles: Tecnólogo em Gestão Empresarial, em Logística, em Gestão Financeira, em Gestão da Tecnologia da Informação, em Análise e Desenvolvimento de Sistemas e em Gestão Comercial.

Com o importante papel da universidade nesse contexto, a unidade se encontra com um posicionamento estratégico podendo tornar-se mais efetiva no desenvolvimento e transferência de tecnologia para evolução sócio econômica da região e do país.

Pode-se considerar a inovação como o principal instrumento do empreendedorismo, é necessário que ela esteja engajada também em todas as atividades da universidade. Sua importância se dá pelo fato de poder ser um instrumento diferenciador tanto para o graduado quanto para o docente em sua prática de formação e atuação. 
Souza et al, 2005 enfatiza que a formação empreendedora tem por princípios a aprendizagem sobre a compreensão do mundo, analisando e definindo as diferentes facetas do seu contexto individual e institucional; com raciocínio criativo e resolução de problemas, não deixando de lado a competitividade, o domínio pessoal, processo no qual é desenvolvido o autoconhecimento e o autodesenvolvimento e a competitividade que faz parte do mundo dos negócios.

$O$ processo educacional da formação emprendedora está em um elemento central que é a participação ativa dos alunos e o que ele já traz de conhecimentos das mais diversas fontes de informação.

Esta teoria está relacionada com a teoria cognitiva de aprendizagem de Ausubel e a teoria da aprendizagem significativa que Moreira (2013) afirma necessitar de duas condições para o processo: "1) o material de aprendizagem deve ser potencialmente significativo e 2) o aprendiz deve apresentar uma predisposição para aprender".

Para Heinonen and Poikkijoki (2006), a intenção de empreender, o conhecimento, a experiência do aprendizado pela prática, a ação por meio da exploração das oportunidades ou necessidades (grifo nosso) e o comportamento empreendedor é o processo pelo qual deve passar a educação empreendedora. Isto remete a uma reflexão que está fundamentada nos estudos de Rae e Yates (1981) que Nassif et al (2011) afirma sobre a referência dessa formação que está no processo do aprendizado teórico, do aprendizado prático e do que o autor chama de aprendizado social é que o aprender a partir dos outros tanto positivo como negativamente, ou seja, empreendedores de sucesso e também os empreendedores que fracassaram em seus negócios e persistiram e os que desistiram.

Nesse contexto, percebe-se a importancia da autonomía no proceso de aprendizagem.

Ao professor cabe o compromisso da construção do conhecimento que para Saul e Saul (2016) deve ser um conhecimento crítico-trasnformador na direção de uma sociedade democrática, justa e solidária, que transborda e penetra a estrutura e o funcionamento de uma instituição de ensino superior.

\section{A investigação do perfil docente dos cursos de formação tecnológica}

Uma das características dos docentes que trabalham nas unidades de ensino tecnológico é possuir uma especificidade em relação a sua formação de professor universitário. Ele é um professor que tem como base a profissão que exerce ou já exerceu; a importância é sua carreira profissional.

Tardif (2010) afirma que na prática docente os profissionais devem se apoiar em conhecimentos especializados e formalizados, na maioria das vezes, por intermédio das disciplinas científicas em sentido amplo, incluindo, as ciências da educação. Para o autor "saber fazer não necessariamente é sinônimo de saber ensinar (p.117) É a base pedagógica que fundamenta as reflexões sobre o ensinar e o aprender, exercício fundamental na prática docentes
Os docentes são selecionados por concurso, que inclui uma prova técnica, aula - teste em que são avaliadas as habilidades didáticas e a avaliação de currículo.

Qual a formação docente dos professores que hoje atuam nos Cursos Superiores de Tecnologia? Qual a importância conferida aos aspectos técnicos e pedagógicos desta formação para a atuação dos professores nos Cursos Superiores de Tecnologia?

"A pouca valorização do conhecimento pedagógico na formação do professor universitário contradiz o discurso acadêmico que defende essa formação específica para outros níveis de ensino. Vive-se uma ambiguidade sobre o que representa o valor para a profissionalidade docente". Cunha (2005, p. 74)

Foi elaborado um questionário com os docentes da instituição com o objetivo de um levantamento sobre identificação dos docentes; o professor e suas escolhas, suas práticas e a política institucional. Esta é a fase em que os professores são os atores principais, por isso, esse diagnóstico é muito importante.

A pesquisa foi dividida em 4 partes: 1) a identificação do corpo docente. 2) o professor e suas escolhas, 3) quanto a prática docente e 4) política institucional.

A pesquisa foi realizada no período de fevereiro/2016 a abril/2016 onde foram realizados também o pré-teste da pesquisa

A unidade hoje possui 65 professores distribuídos nas diversas áreas do conhecimento e um quadro de titulação de docentes variado, o que representa uma variedade de competências que se relacionam com a atitude empreendedora e importantes conhecimentos que devem ser trabalhados neste quesito.

A distribuição da titulação dos docentes pesquisados mostra que $46 \%$ dos respondentes tem como sua última titulação a especialização, $38 \%$ são mestres, $8 \%$ são doutores e $8 \%$ dos docente são apenas graduados.

Como a instituição tem um propósito de desempenhar um papel fundamental na promoção do desenvolvimento econômico na medida em que forma profissionais capacitados para atender a demanda da região, o quadro docente se apresenta bem voltado para o mercado, embora $43 \%$ tenha buscado uma titulação mais acadêmica, o que pode demonstrar uma preocupação dos docentes em relação a sua qualificação enquanto docente do ensino superior.

A busca por titulação não só traz um aperfeiçoamento técnico, mas também um aprendizado acadêmico. O docente adquire um outro olhar para reflexão e análise dos currículos e referenciais para a construção do conhecimento a ser trabalhado com os alunos

Castro (2013) faz uma reflexão de D.Schoen das falas não verbalizadas dos profissionais ao realizar o seu trabalho. Para o autor, são descritas como experiência tácita, ou interstício não codificado entre o que descreve a teoria e o ato de fazer. Daí que: (1) adquire esta metalinguagem que é parte inseparável da profissionalização; (2) apenas verdadeiros profissionais podem transmitir esta dimensão do profissionalismo; (3) leva tempo para formar um profissional.

Com essa reflexão, Castro (2013) afirma que cada disciplina requer professores com perfil específico. Para as disciplinas teóricas, nada melhor do que exigir um 
doutorado. Para o autor, se houvesse doutores com experiência de mercado, tanto melhor. Mas a grande maioria dos programas de doutorados preparam para a pesquisas e para a universidade.

No ensino tecnológico e na grande parte das instituições particulares prevalece a didática do cotidiano, adquirida com a experiência em que se prestigia a valorização da competência em sala de aula.

Gauthier (2014), no seu texto sobre o nascimento da pedagogia, já falava sobre a valorização do conhecimento técnico - bastava somente conhecer a matéria ensinada para ir a sala de aula transmitir esses conhecimentos aos alunos. Tal é, pois, uma das características dos professores técnicos das universidades e da grande maioria dos docentes da mantenedora. Supõe-se ser um perfil de profissionais que muitas vezes não conseguiram encontrar outro trabalho e partiram para o oficio na docência do ensino superior.

Do total de 65 docentes, 40 responderam à pesquisa, equivalendo a $75 \%$ da amostra. Para fins de classificação, os docentes foram distribuídos nas áreas de humanas com $51,43 \%$ dos docentes, exatas com $45,71 \%$, e biológicas com $2,86 \%$.

Para Nóvoa (1992) a atividade de ensino, perante a visão de algumas pessoas, é uma atividade que se realiza com naturalidade, sem qualquer formação específica. E, Comenius (1952) segundo Gauthier (2014), diz que ensinar solidamente é promover aos alunos uma cultura científica, literária e artística.

Para Pachane (2004) a formação de professores do ensino superior é vista como algo supérfluo e desnecessário.

Não se pode deixar de considerar que as atividades socioeconômicas têm um papel fundamental na educação e na formação de novas tecnologias que engendram o desenvolvimento econômico. Mas, para transmitir esse conhecimento é necessário que o docente do ensino superior não tenha apenas uma formação técnica, mas também uma qualificação pedagógica. Entretanto, Anastasiou (2002) afirma que não se tem uma exigência de conhecimentos de base para o magistério no ensino superior e nem uma formação sistemática propiciadora da construção de uma identidade profissional para a docência.

Essa diversidade na área de formação dos docentes vem trazer para a instituição um ponto positivo os diversos olhares e posicionamento para o desenvolvimento das competências que se relacionam a atitudes empreendedoras.

No levantamento foi identificado que a área de conhecimento predominante é a área de humanas com $51 \%$ dos docentes, seguido da área de exatas com $46 \%$ dos docentes e $3 \%$ da área de biológicas. Isso mostra o perfil dos cursos da instituição.

Na instituição a idade média dos docentes é de 43 anos, onde se encontra a menor idade é de 28 anos e a maior idade 75 anos. O quadro docente é representado por $52,5 \%$ do sexo masculino e $47,5 \%$ do sexo feminino seguindo o padrão do último Censu do INEP publicado em 2013.
A pesquisa mostra que o quadro docente apresenta uma forte formação da cultura da instituição onde $47,5 \%$ da amostra trabalha da instituição na classe de 6 a 10 anos e isso pode-se afirmar que a prática está sendo desenvolvida e construída com base na cultura da instituição e daí decorrente a política que ela desenvolve.

O tempo de docência da amostra coletada ficou com um percentual de $25 \%$ nas classes de mais de 15 anos. Este cenário mostra um potencial de trocas, de compartilhamento. Existe aqui um espaço para promoção de uma formação contínua inter - pares com a proposta de refinar as práticas pedagógicas trabalhadas em sala de aula.

Na parte dois do questionário, que trata das escolhas do professor, $63,2 \%$ dos respondentes afirmaram que as razões que o levaram a escolher ser professor está relacionada ao desejo de ensinar e $36,8 \%$ escolheram ser professor por ter horários flexíveis.

E o que é ensinar? Para Goergen (2001, p.11) "educar e ensinar devem ser gestos responsáveis". Para o autor o ensino superior deve ter docente com compromisso, envolvimento, participação crítico-reflexiva e compreensão ampla das políticas educacionais universitárias e suas implicações - lembrando que docência e pesquisa constituem o cerne deste trabalho.

Já para Silva $(2013$, p.3) "ensinar no ensino superior não é ser conselheiro e o foco do professor é a aprendizagem dos alunos sobre sua área de formação e de especialização, para a qual se preparou enquanto profissional competente que deseja ser por meio de seu trabalho"

Se o desejo de ensinar corresponde à maioria dos professores, é importante aqui refletir o que Goergen (2001, p.15) afirma "cabe ao professor universitário a intransferível tarefa de contribuir para a formação e conscientização dos seus alunos", isto é formar cidadãos capazes de pensar e atuar cientificamente. Esse papel implica em formar cidadãos em condições de assumir uma postura crítico-reflexiva diante dos problemas da sociedade na qual está inserido e capazes de interagir e contribuir para a transformação desta sociedade.

O docente, segundo Silva(2013), não pode ser condescendente com os alunos que não tenham adquirido o mínimo necessário para sua profissão ou mesmo sem condições mínimas para se integrar e participar ativamente da sociedade como cidadãos e profissionais responsáveis, verdadeiros, éticos "que sabem o que estão fazendo e dizendo, capazes de decidir com autonomia e preocupação com o bem estar de todos os envolvidos que serão afetados por suas decisões e pelo resultado de seu trabalho"(p.9).

$\mathrm{Na}$ questão "qual foi o motivo que fez você escolher trabalhar na unidade", os principais motivos apontados vão ao encontro da característica do ensino tecnológico estar relacionado ao percentual de docentes que atuam no mercado - por causa da área de conhecimento (sua atuação profissional) embora convite, indicação de colegas /familiares também tenha aparecido com uma grande incidência. 
A parte três do questionário está relacionada à pratica docente. A Figura 1 apresenta o resultado encontrado.

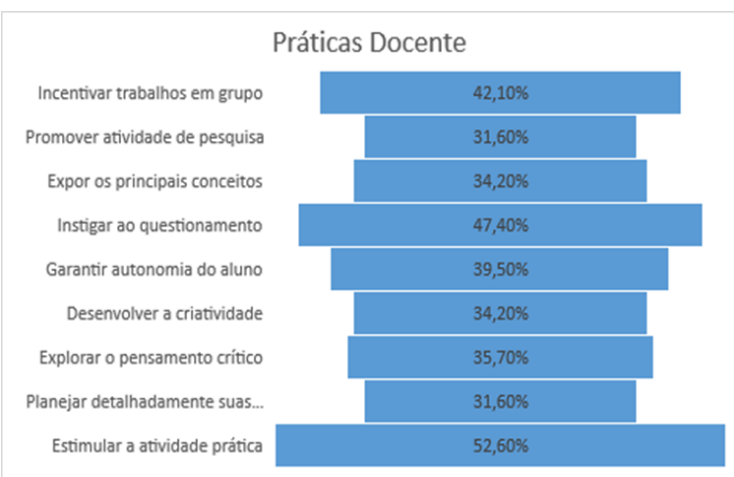

Fonte: elaborado pelos autores (2016)

Figura 1. Práticas docentes

Para Ariza e Toscano (2000) o conhecimento do professor especializado não pode ser reduzido ao conhecimento acadêmico e formal de uma disciplina particular. O conhecimento profissional deve ser organizado em esquemas com o conhecimento teórico e prático alimentando a inclusão dos conteúdos profissionais.

Para os autores, o professor de uma disciplina específica deve conhecer em profundidade o objeto de estudo, problemas, leis e teorias fundamentais da disciplina, bem como conceitos principais que fazem ligação com outros conceitos nas disciplinas próximas, ter algumas informações gerais que lhe permita participar em projetos interdisciplinares com professores de outras especialidades.

Analisando um pouco das práticas citadas, quais as vantagens de trabalhar em grupo?

Todo projeto, toda atividade empresarial é preciso contar com o apoio de uma equipe, com profissionais com visões e ideias diferentes pode trazer enormes vantagens e tornar os processos e ações de uma empresa mais competitivos e melhores para obter resultados significativos e assim garantir que o objetivo final seja alcançado.

Como cada indivíduo possui habilidades específicas para tarefas específicas, as atividades em grupo fazem com que o aumento da aprendizagem seja significativo, pois o convívio faz com que os integrantes troquem experiências e dividam conhecimento, aumentando o aprendizado. Com essas considerações fica aqui registrada a importância de trabalhar esta prática em sala de aula.

Quando se trata de postura empreendedora, a criatividade possibilita uma certa autonomia, pois o mercado e as situações encontradas nas diversas organizações precisam de soluções rápidas para determinados problemas. Para isso, são necessárias ideias que tragam melhorias, ter capacidade de alocar as habilidades criativas para pensar e agir diferente de forma a ser inovador.

Com relação a explorar o questionamento crítico e as atividades de pesquisa seguem algumas considerações.

As atividades de pesquisas no aprendizado dos alunos são importantes porque com a pesquisa identifica, integra e sistematiza o conhecimento, produz e divulga experiências, além de estimular o desenvolvimento de novas pesquisas.

A formação do cidadão é importante e necessária para o desenvolvimento do espírito crítico científico, que é outro olhar, é olhar o mundo de várias maneiras. Para Gadotti (1999), educador e educandos aprendem juntos numa relação dinâmica, na qual a prática, orientada pela teoria, reorienta o processo em um constante aperfeiçoamento. Esse pensar crítico leva a refletir sobre a autonomia intelectual $\mathrm{e}$, com isso, o cidadão pode intervir e transformar a realidade.

É o saber pensar que, conforme Demo (2000), não está somente relacionado com a lógica, mas igualmente na não linearidade da realidade e da vida, é saber manter-se crítico, sobretudo autocrítico, é a arte de argumentar e contra argumentar.

Chimendes (2011) acredita que somente com essas ações é que se desenvolve o espírito crítico e empreendedor nos alunos. Para a autora, a pesquisa é um princípio científico e educativo em que aluno, de modo crítico e criativo, por meio de métodos científicos, reúne informações sobre um determinado problema sempre com a intenção de produzir, aumentar conhecimentos ou até mesmo descobrir algo novo.

Quando se investigou a análise das práticas dos docentes o resultado encontrado foi o apresentado na Tabela 1.

Tabela 1.

Análise das práticas trabalhadas pelos docentes

\begin{tabular}{lc}
\hline \multicolumn{1}{c}{ Análise } & Percentual \\
\hline Faz reflexões & $76,3 \%$ \\
\hline Conversa sobre suas práticas com os colegas & $76,3 \%$ \\
\hline Compartilha com os colegas & $73,7 \%$ \\
\hline Faz algum tipo de registro & $44,7 \%$ \\
\hline Autocritica / auto avaliação & $89,5 \%$ \\
\hline Outros & $7,9 \%$ \\
\hline
\end{tabular}

Fonte: elaborada pelos autores (2016)

Vale considerar que no questionário as alternativas não eram excludentes, com isso era possível assinalar mais de uma alternativa. Com essas respostas também será necessário dar continuidade na pesquisa, pois qual o efeito dessas análises? Isso resulta mudanças nas práticas trabalhadas, revendo a aula pelo aprendizado do aluno?

A totalidade dos entrevistados afirmaram que atualizam suas práticas pedagógicas e novamente mais uma questão precisa ser trabalhada? Como é feita esta atualização?

A última parte do questionário tratava da política institucional. Os respondentes $(50 \%)$ identificaram que a instituição fornece todos os recursos tecnológicos necessários para o desenvolvimento de suas práticas.; $84,2 \%$ responderam que a instituição incentiva parceria com colegas, $39,5 \%$ reconheceram que a instituição faz o acompanhamento do planejamento dos docentes e apenas $36,8 \%$ afirmaram que a instituição promove atualização docente.

\section{Considerações finais}

Nesse contexto é importante refletir e repensar constantemente sobre quais as metodologias de ensino e abordagens pedagógicas ajudam no incentivo do 
aprendizado e nas realizações de atividades da formação empreendedora. Se a aprendizagem instrumentaliza o estudante para exercer sua cidadania de modo emancipatório, não se tem como falar de formação empreendedora se não por meio da autonomia.

Segundo Farias (2006) o professor tem que reconhecer e questionar o seu ensino como uma construção social, buscando desenvolver uma ação transformadora por meio de práticas reflexivas críticas produzidas a partir do cuidado com a emancipação dos alunos, do diálogo com os pares, e do seu engajamento com as questões profissionais e sociais.

O papel do professor como figura central do processo educativo, não se questiona, entretanto, a mudança na educação, no processo de aprendizagem não depende exclusivamente desses profissionais. A responsabilidade do aprendizado está também diretamente ligada às instituições, seus demais atores e gestores, em que o esforço, entusiasmo e criatividade na participação ativa do processo educativo é fundamental.

É preciso que esse professor tenha "habilidade em aprender a aprender", estudo constante e amor e curiosidade pela pesquisa, pois como diz Demo (2004, p.72-73) "a rigor, quem não estuda, não tem aula para dar. Mais: quem não reconstrói conhecimento, não pode fazer o aluno reconstruir conhecimento. Para que o aluno pesquise e elabore, supõe-se professor que pesquise e elabore".

Vale destacar a importância do professor em um programa didático em que o conhecimento é gerado pelos estudantes no processo de elaboração, análise, avaliação e implementação do seu próprio aprendizado, a forma proativa do fazer. O professor nesta relação é a fonte essencial conhecimento/aprendizado.

Ressaltando também que é fundamental na formação empreendedora que os estudantes sejam ativos, participativos e autônomos, nesse processo de aprendizagem.

\section{Referencias}

Anastasiou, L. das G. C Construindo a docência no ensino superior: relação entre saberes pedagógicos e saberes científicos. In: ROSA, D.E. G. \& SOUZA, V.C. (orgs.) (2002) Didáticas e práticas de ensino: interfaces com diferentes saberes e lugares formativos. Rio de Janeiro, Editora DP\&A

Ariza, R. P. Toscano, J.M. (2000) El saber práctico de los profesores especialistas: aportaciones desde las didácticas específicas. In: MOROSINI, Marília Costa. Docência universitária e os desafios da realidade nacional. Professor do ensino superior - identidade, docência e formação. Brasília: INEP/MEC, p. 35- 42.

Castro, A. D. de. (2013) A licenciatura no Brasil. Revista de História (USP) no 100. Set.

Chimendes, V. C. G. (2011) Ciência Tecnologia \&Inovação X Empreendedorismo: diálogos possíveis e necessários Tese Doutorado, UNESP.

Cunha, M. I. (2005) Formatos avaliativos e concepção de docência. 1. ed. Campinas, SP: Autores Associados.
Demo, P. (2000) Conhecer \& Aprender. Porto Alegre: ARTMED.

Demo, P. (2004) Universidade, aprendizagem e avaliação: horizontes reconstrutivos. Porto Alegre: Mediação.

Farias, I. M. S. de. (2006) Inovação, mudança e cultura docente. Brasília: Líberlivro

Gadotti, M.(1999)Convite à leitura de Paulo Freire. São Paulo: Scipione.

Gauthier, C. et al. (2014) Por uma teoria pedagógica: pesquisa contemporâneas sobre o saber docente. Trad. de Francisco Pereira. 2. ed. Ijuí: Unijuí.

Goergen, P. (2001) Pós-modernidade, ética e educação. Campinas, SP: Autores Associados.

Heinonen, J. and Poikkijoki, S.A. (2006), An entrepreneurial-directed approach to entrepreneurship education: mission imposible ? Journal of Management Development, Vol. 25 No.1, pp. 80-94

Moreira, M. A. (2013) Aprendizagem Significativa, Organizadores Prévios, Mapas Conceituais, Diagramas $\mathrm{V}$ e Unidades de Ensino Potencialmente Significativas. Material de apoio para o curso Aprendizagem Significativa no Ensino Superior: Teorias e Estratégias Facilitadoras.

Nassif, V. M. J., Amaral, D .J., Prando, R .A., Lage, M. C., Soares, M .T. R. C. (2011) A Universidade Desenvolve Competências Empreendedoras? Um Mapeamento das Práticas de Ensino Numa Universidade Brasileira. EnPEQ, João Pessoa/ PB.

Nóvoa, A. (1992) A reforma educativa portuguesa: questões passadas e presentes sobre a formação de professores. In: NÓVOA, A.; POPKEWITZ, T. (eds.). Reformas educativas e formação de professores. Lisboa: Educa.

Pachane, G. G. (2004) Teoria e prática na formação pedagógica do professor universitário: elementos para discussão. Publ. UEPG, Ponta Grossa, v. 13, n. 1, p. 1324, jun.

Rae, D., Yates, D. (1981) Equalities. Havard University Press.

Saul, A. M.; Saul, A. (2016) Contribuições de Paulo Freire para a formação de educadores: fundamentos e práticas de um paradigma contra-hegemônico. Educar em Revista, Curitiba, Brasil, n. 61, p. 19-35, jul./set.

Schumpeter, J. A. (1982) Teorias do desenvolvimento econômico: uma investigação sobre lucros, capital, crédito, juro e o ciclo econômico. São Paulo: Abril Cultural. (Os Economistas)

Souza, E. C. L. de., Souza, C. C. L. de, Assis, S. de A. G., Zerbini, T.(2005). Métodos, técnicas e recursos didáticos de ensino de empreendedorismo em IES brasileiras. Anais ANPAD.

Tardif, M. (2010) Saberes docentes e formação profissional. 11. ed. Petrópolis, RJ: Vozes. 